\title{
Welcome to volume 12 of Nanomedicine
}

\author{
"Over the last 10 years, we have seen some great strides in \\ the development of nanotechnology for medical applications. \\ However, there are still a significant number of obstacles that \\ must be overcome before we see a more widespread use of \\ this technology."
}

First draft submitted: 19 October 2016; Accepted for publication: 26 October 2016; Published online: 7 December 2016

Welcome to the 12th volume of Nanomedicine. I would like to take this opportunity to wish all of our readers a Happy New Year. In this short Foreword, I would like to take a look back at some of the journal highlights of 2016.

Last year saw the 10-year anniversary of the launch of Nanomedicine. Over this time, we have seen some great strides in the development of nanotechnology for medical applications. However, there are still a significant number of obstacles that must be overcome before we see a more widespread use of this technology. It has been a great privilege for Nanomedicine to publish the work of researchers involved in this fascinating field, which continues to be of the highest quality. The manuscripts published in 2015 were no exception to this and all contributed to a great year for the journal.

\section{Special focus issues}

A particular highlight of 2016 was to see an unprecedented number of Special Focus issues published in Nanomedicine. Over the course of volume 11, a total of four of these issues were published, one of which was a double-issue. These were:

- Issues 09 and 12: 'Nanobiomaterials at work: revolutionizing healthcare' [1,2]

- Issue 16: 'Nanotechnology for the diagnosis \& treatment of diseases' [3]

- Issue 20: 'Nanoparticles of the immune system: challenges \&opportunities' [4]

- Issue 21: 'Exploitation of functional nanomaterials in therapy and diagnostics' [5]
Special Focus issues are a great way of showcasing the latest research in a specific subfield or concept in nanomedicine. By having an entire journal issue dedicated to a topic, each article can focus on one aspect in detail, contributing to the bigger picture when they are all compiled together. I would like to thank all of the Guest Editors who have aided us in the organization of this year's special focus issues, without whom publication would not be possible.

Outside of our Special Focus issues, we have also published a number of outstanding manuscripts in the journal this year. I had like to draw your attention to some of the particular highlights of 2016.

Our most highly accessed article from volume 11 has been 'Real-time tracking of delayed-onset cellular apoptosis induced by intracellular magnetic hyperthermia' by Blanco-Andujar et al. [6]. In this research article, the authors from University College London (UK) assessed cell death pathways in response to magnetic hyperthermia by loading human melanoma cells with iron oxide nanoparticles and subjecting them to a magnetic field. Their results support the notion that intracellular heating could be used as an effective treatment strategy in diseases such as cancer.

Our second most-accessed article has been a review by Corbo et al. entitled 'The impact of nanoparticle protein corona on cytotoxicity, immunotoxicity and target drug delivery' [7]. This interesting piece tackles the important topic of the protein corona and

\section{Article highlights}

Jonathan Wilkinson

Future Medicine Ltd, Unitec House, London N3 1QB, UK

j.wilkinson@futuremedicine.com
Future fs马 


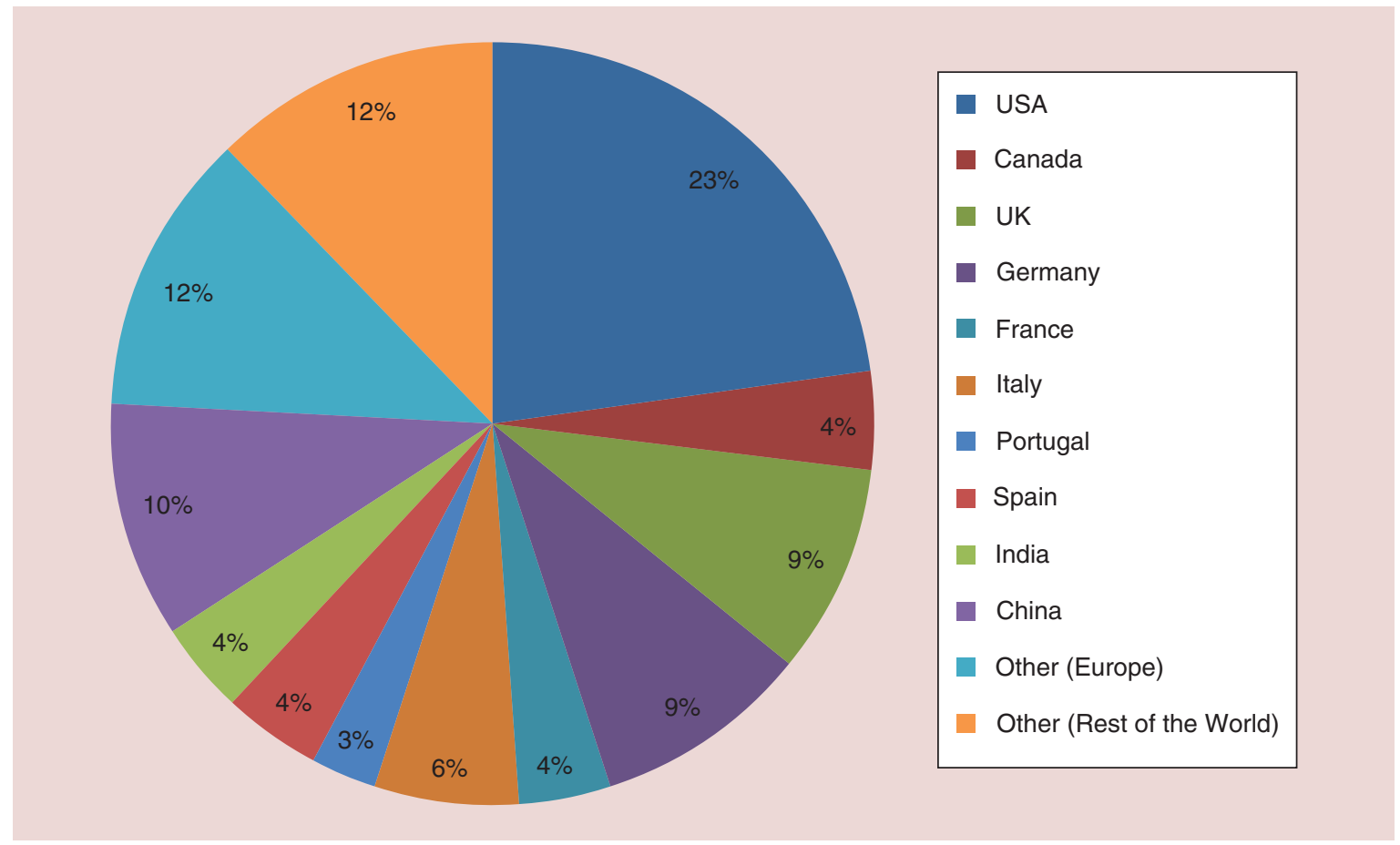

Figure 1. Country of authors published in Nanomedicine Volume 11 (2016).

how it interacts with nanoparticles, further discussing how we might improve the efficacy of targeted delivery of nanocarriers.

Social media is increasingly becoming a powerful means of disseminating research findings and Nanomedicine now uses Altmetrics to measure the impact of our publications in this regard. An excellent example of this has been the research article by Chen et al., entitled 'Chemically activatable viral capsid functionalized for cancer targeting' [8], which has received an impressive Altmetrics score of 168. In this study, the authors designed a capsule using a virus-like nanoparticle for cancer diagnostics and therapeutics. A mixture of tweets, blog posts and stories from news outlets has helped this article reach interested readers from all over the world.

\section{Geographical spread of our contributors}

The editors at Nanomedicine are always interested to see the geographical spread of our authors (Figure 1). As expected, the country we published the most content from in 2016 was the USA (23\%). Of particular note, contributions from China continue to increase, making up $10 \%$ of our published content in 2016. Germany and the UK come next (9\%), followed by a selection of other European nations and India. As can be seen by the diversity of the graph in Figure 1, Nanomedicine receives contributions from a vast number of countries from across the world and we hope to see this continue in the years to come.

\section{Twitter}

As many of you will be aware, Nanomedicine has a Twitter account, which was launched in 2014. We showcase content highlights, journal updates and key news from the nanomedicine field. It has been great interacting with our growing base of followers over the last year and encourage anyone on Twitter to follow us (@fsgnnm).

\section{Conclusion}

I would like to take this opportunity to thank everyone that has made Nanomedicine a success over this last year. This includes the authors who have submitted their work as well as the peer reviewers who kindly give up their time to provide high-quality feedback on the submissions. I would also like to extend my gratitude to the Editorial Board, who continue to support the journal by providing their invaluable advice and assistance. I am looking forward to another successful year for the journal and hope to see yet another volume of fascinating content.

\section{Financial \& competing interests disclosure}

$J$ Wilkinson is an employee of Future Medicine Ltd. The author has no other relevant affiliations or financial involvement with any organization or entity with a financial interest in or financial conflict with the subject matter or materials discussed in the manuscript apart from those disclosed.

No writing assistance was utilized in the production of this manuscript. 


\section{References}

1 Pandit A, Zeugolis DI. Twenty-five years of nano-biomaterials: have we revolutionized healthcare? Nanomedicine (Lond.) 11(9), 985-987 (2016).

2 Pandit A, Zeugolis DI. Structured substrates and delivery vehicles: trending now in biomedicine. Nanomedicine (Lond.) 11(12), 1489-1493 (2016).

3 Azzawi M, Seifalian S, Ahmed W. Nanotechnology for the diagnosis and treatment of diseases. Nanomedicine (Lond.) 11(16), 2025-2027 (2016).

4 Zentel R. Nanomedicine for immunotherapy. Nanomedicine (Lond.) 11(20), 2619-2620 (2016).

5 Sen T. Exploitation of functional nanomaterials in therapy and diagnostics. Nanomedicine (Lond.) 11(21), 2753-2755 (2016).
6 Blanco-Andujar C, Ortega D, Southern P et al. Real-time tracking of delayed-onset cellular apoptosis induced by intracellular magnetic hyperthermia. Nanomedicine (Lond.) 11(2), 121-136 (2016).

7 Corbo C, Molinaro R, Parodi A, Toledano Furman NE, Salvatore F, Tasciotti E. The impact of nanoparticle protein corona on cytotoxicity, immunotoxicity and target drug delivery. Nanomedicine (Lond.) 11(1), 81-100 (2016).

8 Chen C, Xing L, Stark M et al. Chemically activatable viral capsid functionalized for cancer targeting. Nanomedicine (Lond.) 11(4), 377-390 (2016). 